\title{
REVIEW
}

\section{Agrobacterium spp. genes and ORFs: Mechanisms and applications in plant science}

\section{Agrobacterium spp. genes e ORFs: Mecanismos e aplicações em plantas}

\author{
Rishan Kupar Rangslang1 , Ziqi Liu', Henrik Lütken¹, Bruno Trevenzoli Favero ${ }^{1 *}$
}

\author{
${ }^{1}$ University of Copenhagen, Department of Plant and Environmental Sciences, Tåstrup, Denmark \\ *Corresponding author: btf@plen.ku.dk \\ Received in July 31, 2018 and approved in September 9, 2018
}

\begin{abstract}
The bacterial origin of crown gall tumours, Agrobacterium tumefaciens was isolated 100 years ago. 70 years later, the findings that random integration of bacterial DNA into the host plant genome provided the potential of using Agrobacterium as a plant genetic engineering tool. Since the 1980s, Agrobacterium-mediated transformation on wide range of plants began developing rapidly. This review focused on the oncogenes of $A$. rhizogenes which is the causative agent of the hairy root disease and the application of A.rhizogenes in plant science.
\end{abstract}

Index terms: Root oncogenic loci; rolB; rolC; ORF13; ORF14.

\section{RESUMO}

A origem da galha-da-coroa, a bactéria Agrobacterium tumefaciens foi isolada há 100 anos atrás. Setenta anos depois, a descoberta da integração aleatória do DNA bacteriano no genoma da planta hospedeira permitiu a exploração do potencial desta bactéria como ferramenta de engenharia genética de plantas. Desde os anos 80, desenvolveu-se rapidamente a transformação de uma vasta gama de espécies mediada por Agrobacterium. Esta revisão é focada nos oncogenes da A. rhizogenes que é o agente causal da síndrome da raíz de cabeleira e suas aplicações agronômicas.

Termos para indexação: Root oncogenic loci; ro/B; rolC; ORF13; ORF14.

\section{INTRODUCTION}

The search for the causative agent of the crown gall disease, more than a 100 years ago led to isolation of a bacterium from grapevine galls documented by Fridiano Cavara in 1897 in his work published in Le Stazioni Sperimentale, Agrari Italiane. The presence of an unusually large plasmid in A. tumefaciens, which is associated with crown gall formation, was later described (Zaenen et al., 1974). What followed was the findings that a piece of the plasmid DNA would often get transferred and randomly integrated into the genome of the host plant (Zambryski et al., 1980). This is a process that has been and is naturally occurring in nature, which has even contributed to the evolutionary history of certain plant species such as those reported in Nicotania spp. by Chen et al. (2014). This gave rise to numerous studies to better understand the processes and components which the bacterium employs; eventually leading to Agrobacterium playing a key role in plant genetic engineering.

\section{Modification of Agrobacterium for genetic engineering}

The indication that a particular class of plasmids (the Tumor inducing - Ti and Root inducing - Ri plasmids) can transfer their Transfer DNA (T-DNA) segment into a host plant genome (Chilton et al., 1977) was the foundational basis for the proposal of using these plasmids as vectors to introduce foreign genes into plant cells. A number of strategies were developed to introduce foreign genes into the T-DNA; among these strategies, the binary-vector system (Hoekema et al., 1983) brought about a revolution in the use of Agrobacterium for foreign gene introduction into plants. The T-DNA repeats which consists of the left border (LB) and right border (RB) contains a 25 bp sequence that are highly conserved in both $\mathrm{Ri}$ and Ti plasmids (Slightom et al., 1985). These border repeat sequences (LB and RB) are suggested to be the only cis-elements essential for T-DNA transfer (Yadav et al., 1982). The vector harbouring these segments is much smaller, 
easy to modify and may be incorporated with multiple cloning sites, reporter genes, genes for selectable markers and other genes of interest (GOI).

The modification of Agrobacterium by scientists, with little or no specialisation on microbial genetics, can easily be achieved owing to the plasmids being small and uncomplicated for operations in both Escherichia coli and Agrobacterium spp. The presence of multiple unique restriction endonuclease sites within the T-region also proves helpful for cloning the GOI.

\section{The A. rhizogenes Ri plasmid (agropine strain)}

There exists several $A$. rhizogenes strains, which are classified according to the type of opines they catabolise and induce the synthesis of, upon T-DNA integration and expression in the host plant genome (Petit et al., 1983). The Ri-plasmid agropine strain is a split T-DNA plasmid, exhibiting two regions designated as the left T-DNA ( $T_{L}$-DNA) and right T-DNA $\left(T_{R}-D N A\right)$ which are separated by about 15-20 kilobase of non-transferred DNA (White et al., 1985). The $\mathrm{T}_{\mathrm{L}}$-DNA of agropine Riplasmid houses the root oncogenic loci (rol) genes in the central and less conserved region along with other open reading frames (ORFs) (White et al., 1985). The $T_{R}$-DNA harbours two genes iaaM and iaaH, which are responsible for auxin biosynthesis (Camilleri; Jouanin, 1991) as well as a homolog of the rolB gene, called rolB $\operatorname{Tr}$ (Bouchez; Camilleri, 1990). Also present in the Ri plasmid is the virulence region which houses the vir genes (Klee et al., 1983) (Figure 1).

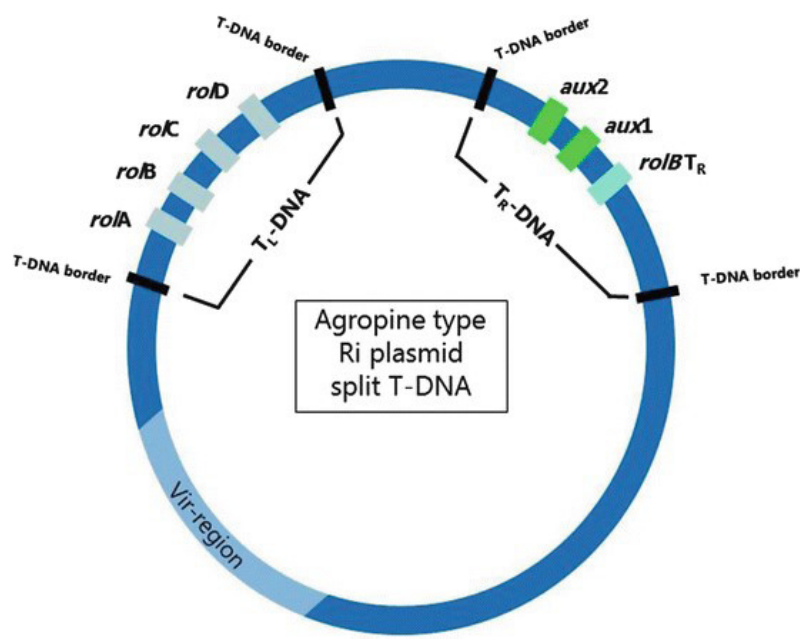

Figure 1: Illustration of the Ri-plasmid (agropine strain) from A. rhizogenes (Lütken et al., 2017).

\section{Molecular machinery of $A$. rhizogenes transformation}

The mechanism for $A$. rhizogenes transformation involves the transfer of a well-defined DNA segment from its Ri plasmid into the host plant's nuclear genome, hereby genetically transforming it (Tepfer, 2017). The molecular machinery required for the T-DNA transport into the host cell involve proteins encoded by the plasmid's vir genes, alongside various host proteins that help facilitate the later stages of this process (Tzfira; Citovsky, 2002).

The process by which $A$. rhizogenes transfers its T-DNA is initiated upon detection of certain phenolic and sugar compounds that are produced from the wounding site of a potential host plant (Loake; Ashby; Shaw, 1988). Phenolic chemicals are perceived by the VirA sensory protein (Shaw et al., 1988) leading to autophosphorylation of the VirA protein and subsequent transphosphorylation of the VirG protein, which results in the activation of the vir operon (Jin et al., 1990).

The combined action of the bacterial VirD1 and VirD2 proteins, involved directly in the processing of the T-DNA, nick the plasmid at the LB and RB border sequences producing a single stranded (ss) T-DNA molecule (Filichkin; Gelvin, 1993). The nicking is in correspondence with the tight (presumably covalent) linkage of the VirD2 protein, through tyrosine 29 (Vogel; Das, 1992) to the 5' end of the resultant ss T-DNA molecule designated as, the T-strand (Dürrenberger et al., 1989). It is this T-strand that is transferred to the host plant cell and not a double stranded T-DNA (Tinland et al., 1994). The T-strand-VirD2 complex that is formed (also called the "immature T-complex") will then be coated with numerous VirE2 molecules (Sen et al., 1989), either in the bacterial export channel or within the host plant cell to form the "mature T-complex" (or simply the "T-complex") of which the latter is more acknowledged (Citovsky et al., 1992). In certain strains of A. rhizogenes (like the agropine strain) it has been found that the virE2 gene (and hence VirE2 protein) is lacking and instead it is substituted by the GALLS gene and GALLS protein, respectively (Hodges; Cuperus; Ream, 2004). The T-complex will then be transported into the host cytoplasm via the virB/virD4 encoded channel (Vergunst et al., 2000) and finally imported into the host nucleus, where it integrates by recombination into the host genome (Gheysen; Villarroel; Van Montagu, 1991).

\section{Open reading frames (ORFs) of the $A$. rhizogenes T-DNA}

Of the 18 ORFs present on the $T_{L}$-DNA, the distinguished $r o l$ genes of which $\operatorname{rol} \mathrm{A}, \operatorname{rol} \mathrm{B}, \operatorname{rol} \mathrm{C}$ and 
rolD have been notably characterised and correspond to the ORFs 10, 11, 12 and 15 respectively (Slightom et al., 1986). Upon transformation of various plant species with the four rol genes (either individually or in combination) dissimilar results were observed in distinctive plant species and divergent phenotypes were generated in various plants and tissues (Spena et al., 1987). The complex nature of genetic interactions that influences the hairy root phenotype, led to a shift in focus of this area's research into specific genes. Individual genes harbouring promoters inducing overexpression, for example the Cauliflower Mosaic Virus (CaMV) 35S promoter, are used to express the genes of interest and assess the phenotype or measure hormone levels. The following are some of the features of the various oncogenes belonging to $A$. rhizogenes.

\section{rolA}

The rolA gene has been observed on all Ri plasmids with the N-terminal half being highly conserved among different strains. The region (at $63 \mathrm{bp}$ ) typical for the rolA promoter was detected within an intron sequence ( $85 \mathrm{bp}$ in length), which is highly conserved among various strains of A. rhizogenes (Magrelli et al., 1994). The promoter region consists of three functional domains which cooperatively operate to regulate expression of rolA (Guivarc'h et al., 1996). Expression of the rolA gene in N. tabacum resulted in considerable decrease of several classes of hormones, such as auxin, gibberellin, cytokinin and abscisic acid; this decrease was dependent on the type of tissue used and the developmental stage (Dehio et al., 1993). In in vitro experiments on leaf discs, rolA was observed to cause rooting (Serino et al., 1994). The expression of rolA in transgenic tomato plants led to an increased tolerance level to the fungal plant pathogen Fusarium oxysporum f. sp. lycopersici (Bettini et al., 2016b). The rolA protein shares structural similarity with that of the papillomavirus E2 DNA-binding domain (Rigden; Carneiro, 1999). The function of the rolA protein is still unknown, although the promoter shares similar sequence to auxin related genes (Carneiro; Vilaine, 1993).

\section{ro/B}

The rolB gene has been found to be present in all Ri-plasmids and it is vital for inducing hairy root formation in transformed plants (Altamura, 2004). The rolB promoter comprises a complex with five domains: A, B, C, D and $\mathrm{E}$, which can interact with various plant regulatory factors leading to gene expression being based on the tissue type, developmental stage and hormonal signals (Capone et al., 1994). The promoter with all five domains present, caused an expression of the gene in the cells which are responsible for the formation of various root tissues, such as in the root cap and the meristems of the cortex and vascular system (Capone et al., 1994). Of these domains, the $\mathrm{B}$ domain seems to be the most crucial in transcription regulation of the rolB gene; deletion of this domain led to the failed expression of $r o l \mathrm{~B}$ in the meristems and caused the rolB not to be induced by auxin (Capone et al., 1994). Among different strains of Agrobacterium, the sequence ACTTTA $(-312 \ldots-307)$ that lies within the B domain has been found to be highly conserved and it is required for tissue specific expression of $r o l \mathrm{~B}$ as well as being a cisregulatory element required to induce gene expression by auxin (Baumann et al., 1999).

The rolB gene of the $A$. rhizogenes agropine strain, has an open reading frame of $777 \mathrm{bp}$ which translates into a 259 amino acid (aa) protein having a molecular weight of $30 \mathrm{kDa}$ (Filippini el al. 1996). It is widely accepted that rolB is the most important of the rol genes, at least in hairy root formation; in tobacco, its expression alone is sufficient enough to produce roots that are often fast growing, highly branched and ageotropic (Cardarelli et al., 1987). Transgenic rolB plants displayed adventitious root formation and remodelled shoot morphology, these include necrosis in leaves, increased flower size and heterostyly and change in leaf shape (Schmülling; Schell; Spena, 1988). There exists a rolB sequence homologue, referred to as the rolBTr which was identified to be at the 3 ' of the auxl gene in the $\mathrm{T}_{\mathrm{R}}$-DNA of $A$. rhizogenes (Bouchez; Camilleri, 1990). The product of rolBTr however is not a functional homologue of the rolB protein, as observed in morphogenic activities of tobacco (Lemcke; Schmülling, 1998). The rolB gene of the agropine type pRiA4 strain encodes a tyrosine phosphatase, which is localised in the plasma membrane and is assumed to play a role in the transfer of the auxin signal (Filippini et al., 1996).

In the rolB protein sequence of the pRiA4 strain, the CX5R motif was detected which is deemed to be responsible for the function of $r o l \mathrm{~B}$ as a tyrosine phosphatase (Lemcke; Schmülling, 1998). Through mutational studies conducted, the root induction function of rolB gains its support; as it was seen that changing specific amino acids or deleting parts of the rolB protein led to a decline in root formation (Moriuchi et al., 2004). The mechanism by which the rolB protein regulate organogenesis is most likely through alteration of the auxin perception (Maurel et al., 1994).

The function of rolB is however, not only limited to root formation; other morphological and biochemical changes have been observed in plants transformed with vectors containing the $\mathrm{rolB}$ gene. Expression of the $\mathrm{rolB}$ gene 
has been seen to cause abnormal formations of flowering meristems in tissue culture (Altamura et al., 1994) and has been reported to increase the $a, b$ chlorophyll content and cause a spike in the non-photochemical quenching activities in transgenic tomato (Bettini et al., 2016a). In the model plant Arabidopsis thaliana, rolB expression resulted in plant dwarfing and premature necrosis of leaves, altered leaf and flower morphology and development of an increased number of inflorescences per rosette area in comparison with the wild type (Kodahl; Müller; Lütken, 2016). Expression of rolB using specific promoters in transgenic tomatoes, exhibited development of parthenocarpic fruits (Carmi et al., 2003). In experiments where tissues isolated from plant stems and peduncles were transformed with rolB, an effect was seen in the formation of various types of meristems with the specificity of differentiation, ascertained by the hormonal balance left over from the initial tissue (Altamura et al., 1994). Moreover, rolB is a strong inducer of secondary metabolism in transgenic plants (Shkryl et al., 2008). Overexpression of rolB in Rubia cordifolia led to a 3 -fold increase in the (AQ) levels (Bulgakov et al., 2003).

\section{rolc}

The rolC oncogene comprises of sequence at 537$543 \mathrm{bp}$ ORFs which codes for 178-180 amino acid proteins. The rolC promoter consists of a myb response constituent that shares a similarity to that Hordeum vulgare myb gene; myb being a transcription factor may regulate the expression of rolC (Hu et al., 2003). A cis-regulatory element which is activated by sucrose is present in the rolC promoter region, which contributes to the activation of the rolC gene (Yokoyama et al., 1994). The RolC protein is localised in the cytosol (Estruch et al., 1991). Plants transformed with rolC under its endogenous promoter displayed a dwarfed phenotype with reduced apical dominance, having lanceolate leaves, yielding early inflorescence and the flowers were quite small with poor pollen production (Schmülling; Schell; Spena,1988). It is stipulated that rolC increases the levels of active cytokinins, this is due to the findings that its protein has a beta-glucosidase activity which enables the release of free active cytokinins from their active conjugates; observed in vitro (Estruch et al., 1991). The expression of the rolC gene provided potential to enhance antioxidant and medicinal properties in in Lactuca sativa (lettuce) (Ismail et al., 2016).

\section{rold}

Unlike the other rol genes, the rolD gene was not detected in all A. rhizogenes strains but only found in the $\mathrm{T}_{\mathrm{L}}$ DNA of agropine strain Ri plasmids (reviewed by Pavlova et al., 2014). It is incapable of inducing root formation, being the only rol gene that cannot do so (Mauro et al., 1996). The rolD is similar to rolB with both of their promoters having a Dof (a transcription factor)-binding element, which probably has a role in auxin induction. Moreover, rolD is also a late-auxin induced gene similar to $r o / \mathrm{B}$, lagging by 4 hours, the difference being that the induction of the rolD promoter decreases at higher auxin levels, unlike the rolB (Mauro et al., 2002). Despite being the least studied gene among the rol genes, RolD is the only protein whose biochemical function has been determined, i.e. as a functional ornithine cyclodeaminase which produces proline by reducing ornithine (Trovato et al., 2001). A major effect of rolD on the morphology of transformed plants is the maintenance of hairy root growth and increase in flowering (Trovato et al., 2001). In transformed plants overexpressing rolD there is an increased production of the pathogenesis-related protein (PR-1), which is produced as a defence response (Bettini et al., 2003).

\section{ORF8}

The ORF8 gene has the longest sequence amongst the genes present on the $T_{L}$-DNA which codes for a protein of 780 aa (Slightom et al., 1986). Phenotypical analysis of the ORF 8 transgenic plants under the CaMV-35S promoter in tobacco showed difference among various research groups with Lemcke et al. (2000) reporting no changes in morphology while Ouartsi et al. (2004) documented alterations in cotyledon morphology and attributing it to auxin-induced cell division and expansion. Meanwhile, Umber, Clément and Otten (2005) observed that the transformed plants showed significant difference in morphology as compared to the untransformed plants, which included hampered growth and rough, mottled leaves having thick and fleshy midribs. The N-terminal domain of ORF8 displayed some homology to the RolB protein while the $\mathrm{C}$-terminus has a small similarity to the iaaM proteins found in A. tumefaciens (Levesque et al., 1988).

\section{ORF13}

The ORF13 is highly conserved among different A. rhizogenes strains and consists of approximately 600 bp (Stieger et al., 2004). The ORF13 promoter is known to be wound-inducible, observed in most tissues. The induction of ORF 13 promoter begins after 5 hours from the wound infliction and it is maintained for 17 hours where it reaches a maximum. This type of expression was seen in tissue that surround the wound and is not systemic. Upon adding of exogenous auxin after wounding, the activity of ORF13 increases, but cytokinin does not seem to have the same effect (Hansen et al., 1997). An 11 bp motif repeats, 
identified in the ORF13 promoter may play a role in wound induction; also, the ORF13 gene expression in tobacco plants displayed a wound-inducible and organ specific expression (Hansen et al., 1997). Phenotypic alterations were detected in transgenic tobacco plants harbouring ORF13, with characteristics such as dwarfing, wrinkled leaves, shortened internodes and roots that are agravitropic in nature (Lemcke; Schmülling, 1998). In A. thaliana overexpression of ORF13 caused extreme dwarfing in which plants were reduced to approx. 1\% biomass (Kodahl et al., 2016).

\section{ORF14}

Little is known about this ORF. It has been found that this gene belongs to the same gene family as that of rolB, rolC, ORF8 and ORF13 (Levesque et al., 1988). Overexpression of ORF14 was reported to have no changes in the transgenic plants' morphology (Lemcke; Schmülling, 1998). It has been seen that ORF13 and ORF14 co-act in synergy with the other rol genes, improving root induction in N. tabacum and Daucus carota (Capone et al., 1989; Aoki; Syno, 1999b); nonetheless, this does not discern the actual functions of the two ORFs.

It is quite peculiar that the region where the ORF14 lies on the Ri plasmid is highly conserved between different strains of $A$. rhizogenes. This could indicate towards an evolutionary advantage in retaining the gene, but in the studies that have been conducted, no morphological effects have been reported. A very narrow range of species have so far been used for the study of transformation with ORF14, hence it is difficult to ascertain the range of effects this ORF might have on transformed plants.

\section{Promising applications of $A$. rhizogenes}

A significant feature of the roots induced by $A$. rhizogenes, is their distinctive ability to grow in vitro without using any exogenous plant growth regulators (Rao; Ravishankar, 2002). In nature, the host range of A. rhizogenes seems to be limited to few plant species; however, under controlled laboratory conditions, around 450 different plant species are found to be susceptible to $A$. rhizogenes infections (reviewed by Porter, 1991). Also, most plant tissues and organs like leafs, hypocotyls, petioles, stems, cotyledons and roots have exhibited the possibility to be transformed by $A$. rhizogenes, which often results in hairy root production with varying degrees of responses depending on the plant species and tissue type (Daud et el., 2015; Sharma; Gambhir; Srivastava, 2014). Moreover, plants transformed with wild type $A$. rhizogenes are not deemed to be designated as genetically modified organisms (GMO) in Japan (Mishiba et al., 2006) and are in line with the EU regulations to not be classified as a GMO (Christensen; Müller, 2009; EU-Commission, 2001). These features of $A$. rhizogenes enable the exploitation of the bacterium in various applications.

\section{A. rhizogenes in plant biotechnological applications}

Promoter analysis and identification of subcellular localisation: Reporter genes encoding either fluorescent proteins (FP) or $\beta$-glucuronidase (GUS) can be used to analyse the function of promoters in hairy roots induced by $A$. rhizogenes. Studies have recently shown that it was successful to use hairy roots in determining the pattern of expression of various promoters fused with either green fluorescent protein (GFP) or GUS reporter genes (Estrada-Navarrete et al., 2007). Furthermore, the probing of subcellular localisation of proteins to various cell organelles can be utilised using hairy roots produced through transformation with $A$. rhizogenes (Ron et al., 2014).

Gene function analysis: RNA interference (RNAi) has been used as a reverse genetic tool for the analysis of gene function. Studies have shown that composite plants, i.e. similar to grafting and developed by Hansen et al. (1989), which involved DsRED1 Medicago trunculata shoots with $A$. thaliana transgenic roots, pointed out to a variable but functional RNAi silencing (Limpens et al., 2004). Using the ex vitro method of composite plant production, it was possible to silence the recombinant GUS and GFP genes in roots of transgenic plants expressing stable GUS or GFP, through the expression of dsRNA to scorable markers in hairy roots induced by A. rhizogenes (Collier et al., 2005).

Secondary metabolite production: In general, hairy root cultures of $A$. rhizogenes are fast growing, easy to maintain, with short doubling time and known to possess the ability to synthesise a vast range of chemical compounds and proteins (Tepfer, 1990). This is advantageous over plant cell suspension cultures when it comes to production of valuable secondary metabolites and foreign proteins. Many interesting plant secondary metabolites are known to accumulate in roots (Tian, 2015), but the harvesting of such roots will have detrimental effects on the plants; hence, the culturing of hairy root cultures would provide a better alternative to the production of secondary metabolites. The efficiency of secondary metabolite production can be substantially enhanced through elicitation, cell permeabilization, precursor feeding and with trapping of the molecules released into the hairy root culture medium of $A$. rhizogenes. 
Phytoremediation: Certain plant species possess the ability to absorb and accumulate heavy metals, sometimes converting the toxic organic molecules into harmless forms (Kumar; Smita; Flores, 2017). Hairy roots induced by $A$. rhizogenes in plants like the Alpine Penny-cress (Thlaspi caerulescens) and Alyssum bertolonii, both being hyperaccumulator plants, have been tested to take up nickel or cadmium from polluted soil or water (Malik et al., 2016). Additionally, hairy roots of B. napus, B. juncea, and Chicorium intybus have been observed to significantly detoxify the extensively used pesticide dichlorodiphenyltrichloroethane (DDT) and the herbicide 2,4-dicholophenol (2,4-DPC) from industrial effluents (Malik et al., 2016).

\section{Utilising A. rhizogenes in crop \& ornamental plants}

Phenotypic alterations of useful crop species: Transformation of beneficial crop species with $A$. rhizogenes can lead to changes in plant morphology which are sometimes desirable or fitting with the situational requirement. For example, Arshad et al. (2014) showed that $L$. esculentum transformed with the rolB gene led to a significant change in the vegetative growth, with the transgenic plants being smaller in height and bearing smaller berries as compared to the wild type. The transgenic tomato plants also had a significant increase of 18 to $62 \%$ in their lycopene content which was indicative of a boost in their nutritional value (Arshad et al., 2014). Another example can be seen in one of the major oil crops; oil seed rape ( $B$. napus), which showed an increase in branch numbers as well as reduction in height of plants transformed with wild type $A$. rhizogenes and most interestingly an increase in $\alpha$-linolenic acid content (Hegelund et al., 2018).

Enhanced rooting in bare root stocks: A. rhizogenes is known to induce highly branched root systems in transformed tissues. Hence, the intentional treatment on bare root stocks (technique whereby plants are removed from the soil during their dormant state and moved to new soil conditions where they can readily acclimatise) which essentially requires root initiating activity, is quite beneficial and can help tackle certain problems associated with its relative operations. This is mostly the case with young plants which are propagated by the bare root technique, as the root is nearly functionless, unable to provide water to the plant until formation of secondary roots with abundant root hairs. This technique has been tested in bare root stock of almond trees (Prunus amygdalus) which had been treated with $A$. rhizogenes; this resulted in the bare root stocks accumulating larger root number and root mass as compared to the controls (Strobel;
Nachmias, 1985). The same was done for bare root stock of olive trees (Olea europaea) which resulted in trees having a large ratio of new root to old root mass and a larger root mass in total. The trees even grew relatively quicker than the un-transformed trees and produced significantly higher number of flowers and fruits after a period of three years (Strobel; Nachmias; Hess, 1988).

As a breeding tool for ornamental plants: In the horticultural industry certain morphological characteristics such as: dwarfing, increased branching, increased inflorescence and compactness are desirable features for potted plants (Lütken et al., 2017). Transformation of Kalanchoë blossfeldiana with $A$. rhizogenes yielded lines with altered morphological traits that can be of ornamental value (Christensen et al., 2008). The rose bush (Rosa hybrida) transformed with the rolC gene gave rise to a dwarfed phenotype with increased lateral branching and reduced root system; leaves were chlorotic and wrinkled and the flowers were comparatively smaller having reduced fertility (Souq et al., 1995). In Osteospermum ecklonis lines with 35S::rolC showed stronger promotion towards flowering with an increased number of flowers on each plant, as well as the early onset of flowering (Giovannini et al., 1999).

\section{Role of rol genes on plant secondary metabolism}

Plants produce many diverse compounds which include anthraquinones, saponins, flavonoids, alkaloids, anthocyanins and terpenes which play an important role in various industries (Tian, 2015). Many of these compounds are produced by plants through secondary metabolism; these metabolites are usually non-essential for the growth of plants, hence the amount produced is often quite low (Kim; Wyslouzi; Weathers, 2002; Matveeva; Sokornova; Lutova, 2015).

As mentioned earlier, hairy root cultures generated by the transformation of certain plant species by $A$. rhizogenes can be a valuable tool for the production of secondary metabolites in plants. A large number of dicotyledonous as well as monocotyledonous plant's hairy root cultures have been found to produce similar secondary metabolites as those found in natural roots (Rudrappa et al., 2005). In recent years, it has been reported that the rol genes (rolA, rolB and rolC) of $A$. rhizogenes are known to confer novel features in plant cells when transformed, either as individual genes or in combination of the three (Bulgakov, 2008).

In dried leaves and stems of Artemisia dubia plants transgenic with rolA, the level of artemisinin was significantly elevated (Amanullah et al., 2016). 
Resveratrol, an important stilbene that is capable of preventing fungal infections in plants (Dixon; Harrison, 1990) was seen to be effectively increased over a hundredfold, when Vitis amurensis was transformed with the rolB gene (Kiselev et al., 2007). Also, calli obtained from explants of Maackia amurensis transformed with rolB led to high accumulation of isoflavonoids upon high expression of this rol gene (Grishchenko et al., 2016).

High concentrations of ginsenoside, which exceeded the parent calli by almost 3 times, were demonstrated in roots of the Panax ginseng by transformation of the callus line with rolC (Bulgakov, 1998). The rolC gene is said to exhibit an activator effect, independent of the cell differentiation level; this was deduced from the presence of equal levels of ginsenosides in both transformed roots and calli (Bulgakov, 1998). In rolC transgenic lines of $L$. sativa, an increase in the total phenolic contents and similarly in flavonoid content was reported (Ismail et al., 2016).

Of the three oncogenes of $A$. rhizogenes, the rolB gene seems to be the most powerful inducer of secondary metabolism in transformed plants. However, when in combination with the rolA and rolC genes in a construct harbouring all three genes $(\operatorname{rol~A}, \mathrm{B}$ and C) together, the effect of $r o l \mathrm{~B}$ in rapid growth of transformed cells was reduced (Shkryl et al., 2008). Similarly, the stimulatory effect of rolB on AQ accumulation was the highest when comparing to that of rolA or rolC, but the effect of rolB was reduced when combined with the rolA and rolC genes (Bulgakov, 2008). It seems likely that the rolC gene may be conferring a wider spectrum of defence reactions, besides stimulation of secondary metabolites, this is evident in rolC expressed in ginseng cells, the expression of which correlated to activation of $\beta$-1,3-glucanase, which is a part of the plant defence proteins, PR-2 family (Kiselev et al., 2006).

\section{CURRENT AND FUTURE NEEDS}

Collectively, the rol genes have been used in trial and error approaches and generated valuable phenotypes mostly to the ornamental plant industry. A more targeted research is required in this area to efficiently utilize Agrobacterium-mediated systems of transformation, which is still lacking in knowledge, especially on the effect and function of the individual genes and ORFs of A. rhizogenes. Techniques like the overexpression of a single gene, co-expression with fluorescent proteins and endogenous promoter studies will provide information for a better understanding of natural transformation techniques. The elucidation of the copy numbers of inserted genes and the preferred integration sites of
T-DNA transferred into foreign host cells along with gene expression analyses and protein characterizations could pave the way for augmenting the capabilities essential to the field of genetic engineering by Agrobacterium.

\section{ACKNOWLEDGEMENTS}

The Danish Council for Independent Research supported this research (Grant n. DFF-7017-00197).

\section{REFERENCES}

ALTAMURA, M. M. Agrobacterium rhizogenes rolB and ro/D genes: Regulation and involvement in plant development. Plant Cell, Tissue and Organ Culture, 77(1):89-101, 2004.

ALTAMURA, M. M. et al. The plant oncogene rolB stimulates the formation of flower and root meristemoids in tobacco thin cell layers. New Phytologist, 126(2):283-293, 1994.

AMANULLAH, B. M. et al. Production of artemisinin and its derivatives in hairy roots of Artemisia dubia induced by rola gene transformation. Pakistan Journal of Botany, 48(2):699-706, 2016.

AOKI, S.; SYŌNO, K. Synergistic function of rolB, rolC, ORF13 and ORF14 of TL-DNA of Agrobacterium rhizogenes in hairy root induction in Nicotiana tabacum. Plant and Cell Physiology, 40(2):252-256, 1999b.

ARSHAD, W. et al. Agrobacterium-mediated transformation of tomato with ro/B gene results in enhancement of fruit quality and foliar resistance against fungal pathogens. PLoS One, 9(5):e96979, 2014.

BAUMANN, K. et al. The DNA binding site of the Dof protein NtBBF1 is essential for tissue-specific and auxin-regulated expression of the ro/B oncogene in plants. The Plant Cell, 11(3):323-333, 1999.

BETTINI, P. P. et al. Agrobacterium rhizogenes ro/B gene affects photosynthesis and chlorophyll content in transgenic tomato (Solanum lycopersicum L.) plants. Journal of plant Physiology, 204(2016):27-35, 2016 a.

BETTINI, P. et al. Pleiotropic effect of the insertion of the Agrobacterium rhizogenes rolD gene in tomato (Lycopersicon esculentum Mill.). Theoretical and Applied Genetics, 107(5):831-836, 2003.

BETTINI, P. P. et al. Agrobacterium rhizogenes rolA gene promotes tolerance to Fusarium oxysporum $f$. sp. Iycopersici in transgenic tomato plants (Solanum lycopersicum L.). Journal of Plant Biochemistry and Biotechnology, 25(3):225-233, 2016b. 
BOUCHEZ, D.; CAMILLERI, C. identification of a putative rol B gene on the TR-DNA of the Agrobacterium rhizogens A4 Ri plasmid. Plant Molecular Biology, 14(4):617-619, 1990.

BULGAKOV, V. P. Functions of rol genes in plant secondary metabolism. Biotechnology Advances, 26(4):318-324, 2008.

BULGAKOV, V. P. et al. The impact of plant rolC oncogene on ginsenoside production by ginseng hairy root cultures. Phytochemistry, 49(7):1929-1934, 1998.

BULGAKOV, V. P. et al. Increase in anthraquinone content in Rubia cordifolia cells transformed by rol genes does not involve activation of the NADPH oxidase signaling pathway. Biochemistry, 68(7):795-801, 2003.

CAMILLERI, C.; JOUANIN, L. The TR-DNA Region carrying the auxin synthesis genes of the Agrobacterium rhizogenes Agropine-Type plasmid pRiA4: Nucleotide sequence analysis and introduction into tobacco plants. Molecular Plant-Microbe Interactions, 4(2):155-162, 1991.

CAPONE, I. et al. Expression in different populations of cells of the root meristem is controlled by different domains of the ro/B promoter. Plant Molecular Biology, 25(4):681-691, 1994.

CAPONE, I. et al. Induction and growth properties of carrot roots with different complements of Agrobacterium rhizogenes T-DNA. Plant Molecular Biology, 13(1):43-52, 1989.

CARDARELLI, M. et al. Agrobacterium rhizogenes T-DNA genes capable of inducing hairy root phenotype. Molecular and General Genetics, 209(3):475-480, 1987.

CARMI, N. et al. Induction of parthenocarpy in tomato via specific expression of the ro/B gene in the ovary. Planta, 217(5):726735, 2003.

CARNEIRO, M.; VILAINE, F. Differential expression of the rolA plant oncogene and its effect on tobacco development. The Plant Journal, 3(6):785-792, 1993.

CHEN, K. et al. Deep sequencing of the ancestral tobacco species Nicotiana tomentosiformis reveals multiple T-DNA inserts and a complex evolutionary history of natural transformation in the genus Nicotiana. The Plant Journal, 80(4):669-682, 2014.

CHILTON, M. D. et al. Stable incorporation of plasmid DNA into higher plant cells: The molecular basis of crown gall tumorigenesis. Cell, 11(2):263-271, 1977.

CHRISTENSEN, B.; MÜLLER, R. The use of Agrobacterium rhizogenes and its rol-genes for quality improvement in ornamentals. European Journal of Horticultural Science, 74(6):275, 2009.
CHRISTENSEN, B. et al. Transformation of Kalanchoe blossfeldiana with rol-genes is useful in molecular breeding towards compact growth. Plant Cell Reports, 27(9):14851495, 2008.

CITOVSKY, V. et al. Nuclear localization of Agrobacterium VirE2 protein in plant cells. Science, 256(5065):1802-1805, 1992.

COLLIER, R. et al. Ex vitro composite plants: An inexpensive, rapid method for root biology. The Plant Journal, 43(3):449-457, 2005.

DAUD, N. F. A. et al. In vitro regeneration of Brassica oleracea var. capitata trough steams, roots, leaves and petioles cultures. In: International Conference on Agricultural, Ecological and Medical Sciences (AEMS-2015) April. 2015. p.7-8.

DEHIO, C. et al. Phenotype and hormonal status of transgenic tobacco plants overexpressing the rolA gene of Agrobacterium rhizogenes T-DNA. Plant Molecular Biology, 23(6):1199-1210, 1993.

DIXON, R. A.; HARRISON, M. J. Activation, structure, and organization of genes involved in microbial defense in plants. Advances in Genetics, 28:165-234, 1990.

DÜRRENBERGER, F. et al. Covalently bound VirD2 protein of Agrobacterium tumefaciens protects the T-DNA from exonucleolytic degradation. Proceedings of the National Academy of Sciences, 86(23):9154-9158, 1989.

ESTRADA-NAVARRETE, G. et al. Fast, efficient and reproducible genetic transformation of Phaseolus spp. by Agrobacterium rhizogenes. Nature Protocols, 2(7):1819, 2007.

ESTRUCH, J. J. et al. Cytosolic localization in transgenic plants of the ro/C peptide from Agrobacterium rhizogenes. Plant Molecular Biology, 17(3):547-550, 1991.

EU-COMMISSION. Directive 2001/18/EC of the European Parliament and of the Council of 12 March 2001 on the deliberate release into the environment of genetically modified organisms and repealing Council Directive 90/220. EEC. 2001.

FILICHKIN, S. A.; GELVIN, S. B. Formation of a putative relaxation intermediate during T-DNA processing directed by the Agrobacterium tumefaciens VirD1, D2 endonuclease. Molecular Microbiology, 8(5):915-926, 1993.

FILIPPINI, F. et al. A plant oncogene as a phosphatase. Nature, 379(6565):499, 1996.

FRUGIS, G. et al. Agrobacterium rhizogenes rol genes induce productivity-related phenotypical modifications in "creeping-rooted" alfalfa types. Plant Cell Reports, 14(8), 488-492, 1995. 
GHEYSEN, G.; VILLARROEL, R.; VAN MONTAGU, M. Illegitimate recombination in plants: A model for T-DNA integration. Genes \& Development, 5(2):287-297, 1991.

GIOVANNINI, A. et al. Ornamental traits modification by rol genes in Osteospermum ecklonis transformed with Agrobacterium tumefaciens. In Vitro Cellular \& Developmental Biology-Plant, 35(1):70-75, 1999.

GRISHCHENKO, O. V. et al. ro/B gene-induced production of isoflavonoids in transformed Maackia amurensis cells. Applied Microbiology and Biotechnology, 100(17):7479-7489, 2016.

GUIVARC'H, A. et al. Tissue-specific expression of the rolA gene mediates morphological changes in transgenic tobacco. Plant Molecular Biology, 30(1):125-134, 1996.

HANSEN, G. et al. Wound-inducible and organ-specific expression of ORF13 from Agrobacterium rhizogenes 8196 T-DNA in transgenic tobacco plants. Molecular and General Genetics, 254(3):337-343, 1997.

HANSEN, J. et al. Hairy roots: A short cut to transgenic root nodules. Plant Cell Reports, 8(1):12-15, 1989.

HEGELUND, J. N. et al. Increasing genetic variability in oilseed rape (Brassica napus): Genotypes and phenotypes of oilseed rape transformed by wild type Agrobacterium rhizogenes. Plant Science, 271:20-26, 2018.

HODGES, L. D.; CUPERUS, J.; REAM, W. Agrobacterium rhizogenes GALLS protein substitutes for Agrobacterium tumefaciens single-stranded DNA-binding protein VirE2. Journal of Bacteriology, 186(10):3065-3077, 2004.

HOEKEMA, A. et al. A binary plant vector strategy based on separation of vir-and T-region of the Agrobacterium tumefaciens Ti-plasmid. Nature, 303(5913):179, 1983.

$\mathrm{HU}, \mathrm{Y}$. et al. Promoter of the ro/C gene of Agrobacterium rhizogenes can be strongly regulated in glandular cell of transgenic tobacco. Molecular Biotechnology, 24(2):121-125, 2003.

ISMAIL, $\mathrm{H}$. et al. Transformation of Lactuca sativa $\mathrm{L}$. with rol $C$ gene results in increased antioxidant potential and enhanced analgesic, anti-inflammatory and antidepressant activities in vivo. 3 Biotech, 6(2):215, 2016.

JIN, S. G. et al. Phosphorylation of the VirG protein of Agrobacterium tumefaciens by the autophosphorylated VirA protein: Essential role in biological activity of VirG. Journal of Bacteriology, 172(9):4945-4950, 1990.

KIM, Y.; WYSLOUZIL, B. E.; WEATHERS, P.J. Secondary metabolism of hairy root cultures in bioreactors. In Vitro Cellular \& Developmental Biology-Plant, 38(1):1-10, 2002.
KISELEV, K. V. et al. The ro/B gene-induced overproduction of resveratrol in Vitis amurensis transformed cells. Journal of Biotechnology, 128(3):681-692, 2007.

KISELEV, K. V. et al. The ro/C gene induces expression of a pathogenesis-related $\beta$-1, 3-glucanase in transformed ginseng cells. Phytochemistry, 67(20):2225-2231, 2006.

$\mathrm{KLEE}, \mathrm{H}$. J. et al. Mutational analysis of the virulence region of an Agrobacterium tumefaciens Ti plasmid. Journal of Bacteriology, 153(2):878-883, 1983.

KODAHL, N.; MÜLLER, R.; LÜTKEN, H. The Agrobacterium rhizogenes oncogenes ro/B and ORF13 increase formation of generative shoots and induce dwarfism in Arabidopsis thaliana (L.) Heynh. Plant Science, 252:22-29, 2016.

KOLTUNOW, A. M. et al. Expression of ro/B in apomictic Hieracium piloselloides Vill. causes ectopic meristems in planta and changes in ovule formation, where apomixis initiates at higher frequency. Planta, 214(2):196-205, 2001.

KUMAR, B.; SMITA, K.; FLORES, L. C. Plant mediated detoxification of mercury and lead. Arabian Journal of Chemistry, 10:S2335-S2342, 2017.

LEMCKE, K.; SCHMÜLLING, T. A putative ro/B gene homologue of the Agrobacterium rhizogenes TR-DNA has different morphogenetic activity in tobacco than ro/B. Plant Molecular Biology, 36(5):803-808, 1998.

LEMCKE, K. et al. The ORF8 gene product of Agrobacterium rhizogenes TL-DNA has tryptophan 2-monooxygenase activity. Molecular Plant-Microbe Interactions, 13(7):787790, 2000.

LEVESQUE, H. et al. Common evolutionary origin of the central portions of the Ri TL-DNA of Agrobacterium rhizogenes and the Ti T-DNAs of Agrobacterium tumefaciens. Plant Molecular Biology, 11(6), 731-744, 1988.

LIMPENS, E. et al. RNA interference in Agrobacterium rhizogenes-transformed roots of Arabidopsis and Medicago truncatula. Journal of Experimental Botany, 55(399):983992, 2004.

LOAKE, G.J.; ASHBY, A. M.; SHAW, C. H. Attraction of Agrobacterium tumefaciens C58C1 towards sugars involves a highly sensitive chemotaxis system. Microbiology, 134(6):14271432, 1988.

LÜTKEN, H. et al. Hairy root cultures of Rhodiola rosea to increase valuable bioactive compounds. In: Production of plant derived natural compounds through hairy root culture. Springer, 2017, p.65-88. 
MAGRELLI, A. et al. Splicing of the rolA transcript of Agrobacterium rhizogenes in Arabidopsis. Science, 266(5193):1986-1988, 1994.

MALIK, S. et al. Biotechnological approaches for bioremediation: In vitro hairy root culture. Transgenesis and Secondary Metabolism, 1-23, 2016.

MATVEEVA, T. V.; SOKORNOVA, S. V.; LUTOVA, L. A. Influence of Agrobacterium oncogenes on secondary metabolism of plants. Phytochemistry Reviews, 14(3):541-554, 2015.

MAUREL, C. et al. Alterations of auxin perception in ro/Btransformed tobacco protoplasts (time course of ro/B mRNA expression and increase in auxin sensitivity reveal multiple control by auxin). Plant Physiology, 105(4):1209-1215, 1994.

MAURO, M. L. et al. Oligogalacturonides inhibit the induction of late but not of early auxin-responsive genes in tobacco. Planta, 215(3):494-501, 2002.

MAURO, M. L. et al. The plant oncogene rolD stimulates flowering in transgenic tobacco plants. Developmental Biology, 180(2):693-700, 1996.

MISHIBA, K. I. et al. Production of dwarf potted gentian using wild-type Agrobacterium rhizogenes. Plant Biotechnology, 23(1):33-38, 2006.

MORIUCHI, $\mathrm{H}$. et al. Nuclear localization and interaction of Ro/B with plant 14-3-3 proteins correlates with induction of adventitious roots by the oncogene ro/B. The Plant Journal, 38(2):260-275, 2004.

OUARTSI, A. et al. The T-DNA ORF8 of the cucumopine-type Agrobacterium rhizogenes Ri plasmid is involved in auxin response in transgenic tobacco. Plant Science, 166(3):557567,2004

PAVLOVA, O. A. et al. Rol-Genes of Agrobacterium rhizogenes. Russian Journal of Genetics: Applied Research, 4(2):137-145, 2014

PETIT, A. et al. Further extension of the opine concept: Plasmids in Agrobacterium rhizogenes cooperate for opine degradation. Molecular and General Genetics, 190(2), 204 $214,1983$.

PORTER, J. R.; FLORES, H. Host range and implications of plant infection by Agrobacterium rhizogenes. Critical Reviews in Plant Sciences, 10(4):387-421, 1991.

RAO, S. R.; RAVISHANKAR, G. A. Plant cell cultures: Chemical factories of secondary metabolites. Biotechnology Advances, 20(2):101-153, 2002.

RON, M. et al. Hairy root transformation using Agrobacterium rhizogenes as a tool for exploring cell type-specific gene expression and function using tomato as a model. Plant Physiology, 166:455-469, 2014.
RIGDEN, D. J.; CARNEIRO, M. A structural model for the rolA protein and its interaction with DNA. Proteins: Structure, Function, and Bioinformatics, 37(4):697-708, 1999.

RUDRAPPA, T. et al. Peroxidase production from hairy root cultures of red beet (Beta vulgaris). Electronic Journal of Biotechnology, 8(2):66-78, 2005.

SCHMÜLLING, T.; SCHELL, J.; SPENA, A. Single genes from Agrobacterium rhizogenes influence plant development. The EMBO Journal, 7(9):2621-2629, 1988.

SEN, P. A. R. T. H. A. et al. Cooperative binding of Agrobacterium tumefaciens VirE2 protein to single-stranded DNA. Journal of Bacteriology, 171(5):2573-2580, 1989.

SERINO, G. et al. rol genes of Agrobacterium rhizogenes cucumopine strain: Sequence, effects and pattern of expression. Plant Molecular Biology, 26(1):415-422, 1994.

SHARMA, S.; GAMBHIR, G.; SRIVASTAVA, D. K. High frequency organogenesis in cotyledon and hypocotyl explants of cabbage (Brassica oleracea L. var. capitata). National Academy Science Letters, 37(1):5-12, 2014.

SHAW, C. H. et al. virA and virG are the Ti-plasmid functions required for chemotaxis of Agrobacterium tumefaciens towards acetosyringone. Molecular Microbiology, 2(3): 413-417, 1988

SHKRYL, Y. N. et al. Individual and combined effects of the rolA, $B$, and $C$ genes on anthraquinone production in Rubia cordifolia transformed calli. Biotechnology and Bioengineering, 100(1):118-125, 2008.

SLIGHTOM, J. L. et al. Nucleotide sequence analysis of TLDNA of Agrobacterium rhizogenes agropine type plasmid. Identification of open reading frames. Journal of Biological Chemistry, 261(1):108-121, 1986.

SLIGHTOM, J. L. et al. Isolation and identification of TL-DNA/ plant junctions in Convolvulus arvensis transformed by Agrobacterium rhizogenes strain A4. The EMBO Journal, 4(12):3069-3077, 1985

SMITH, E. F.; TOWNSEND, C. O. A plant-tumor of bacterial origin. Science, 25:671-673, 1907.

SOUQ, F. et al. Genetic transformation of roses, 2 examples: One on morphogenesis, the other on anthocyanin biosynthetic pathway. In: II International Rose Symposium 424. 1995, p.381-388.

SPENA, A. et al. Independent and synergistic activity of rolA, B and $C$ loci in stimulating abnormal growth in plants. The EMBO Journal, 6(13):3891-3899, 1987. 
SRIVASTAVA, S.; SRIVASTAVA, A. K. Hairy root culture for massproduction of high-value secondary metabolites. Critical Reviews in Biotechnology, 27(1):29-43, 2007.

STIEGER, P. A. et al. The orf13 T-DNA gene of Agrobacterium rhizogenes confers meristematic competence to differentiated cells. Plant Physiology, 135(3):1798-1808, 2004.

STROBEL, G. A.; NACHMIAS, A. Agrobacterium rhizogenes promotes the initial growth of bare root stock almond. Microbiology, 131(5):1245-1249, 1985.

STROBEL, G. A.; NACHMIAS, A.; HESS, W. M. Improvements in the growth and yield of olive trees by transformation with the Ri plasmid of Agrobacterium rhizogenes. Canadian Journal of Botany, 66(12):2581-2585, 1988.

TEPFER, D. DNA transfer to plants by Agrobacterium rhizogenes: A model for genetic communication between species and biospheres. In: JHA, S. (Eds) Transgenesis and secondary metabolism. Springer, Cham. 2017. p.3-43.

TEPFER, D. Genetic transformation using Agrobacterium rhizogenes. Physiologia Plantarum, 79(1):140-146, 1990.

TIAN, L. Using hairy roots for production of valuable plant secondary metabolites. In: Filaments in bioprocesses. Springer, 2015, p.275-324.

TINLAND. B.; HOHN. B.; PUCHTA, H. Agrobacterium tumefaciens transfers single-stranded transferred DNA (T-DNA) into the plant cell nucleus. Proceedings of the National Academy of Sciences, 91(17):8000-8004, 1994.

TROVATO, M. et al. The plant oncogene rolD encodes a functional ornithine cyclodeaminase. Proceedings of the National Academy of Sciences, 98(23):13449-13453, 2001.
TZFIRA, T.; CITOVSKY, V. Partners-in-infection: Host proteins involved in the transformation of plant cells by Agrobacterium. Trends in Cell Biology, 12(3):121-129, 2002.

UMBER, M.; CLÉMENT, B.; OTTEN, L. The T-DNA oncogene A4-orf8 from Agrobacterium rhizogenes A4 induces abnormal growth in tobacco. Molecular Plant-Microbe Interactions, 18(3):205211, 2005.

VERGUNST, A. C. et al. VirB/D4-dependent protein translocation from Agrobacterium into plant cells. Science, 290(5493):979982, 2000.

VOGEL, A. M.; DAS, A. Mutational analysis of Agrobacterium tumefaciens virD2: Tyrosine 29 is essential for endonuclease activity. Journal of Bacteriology, 174(1):303-308, 1992.

WHITE, F. F. et al. Molecular and genetic analysis of the transferred DNA regions of the root-inducing plasmid of Agrobacterium rhizogenes. Journal of Bacteriology, 164(1):33-44, 1985.

YADAV, N. S. et al. Short direct repeats flank the T-DNA on a nopaline Ti plasmid. Proceedings of the National Academy of Sciences, 79(20):6322-6326, 1982.

YOKOYAMA, R. et al. The rolC promoter of Agrobacterium rhizogenes Ri plasmid is activated by sucrose in transgenic tobacco plants. Molecular and General Genetics, 244(1):1522, 1994.

ZAENEN, I. et al. Supercoiled circular DNA in crown gall inducing Agrobacterium strains. Journal of Molecular Biology, 86:109-127, 1974.

ZAMBRYSKI, P. et al. Tumor DNA structure in plant cells transformed by A. tumefaciens. Science, 209:1385-1391, 1980. 